\title{
No association of the insulin gene VNTR polymorphism with polycystic ovary syndrome in a Han Chinese population
} Yuping $\mathrm{Xu}^{1}{ }^{1}$, Zhaolian Wei ${ }^{1}$, Zhiguo Zhang1, Qiong Xing ${ }^{1}$, Pin $\mathrm{Hu}^{1}$, Xiaohui Zhang1, Guihua Gao ${ }^{1}$, Yong Wang ${ }^{2}$, Qian $\mathrm{Gao}^{2}$, Long Yi*2 and Yunxia Cao*1

\author{
Address: ${ }^{1}$ Department of Obstetrics \& Gynecology, the First Affiliated Hospital, Anhui Medical University, Hefei, 230022, China and ${ }^{2}$ Department \\ of Pathology, Nanjing University Medical School, Nanjing, 210093, China \\ Email: Yuping Xu - allin0701@gmail.com; Zhaolian Wei - weizhaolian_1@126.com; Zhiguo Zhang - zzg_100@163.com; \\ Qiong Xing - joan2004207@gmail.com; Pin Hu - sayhow@sohu.com; Xiaohui Zhang - cathyzxh4322@163.com; \\ Guihua Gao - gaoguihua2006@163.com; Yong Wang - wy_518@yahoo.com.cn; Qian Gao - qian_gao@nju.edu.cn; \\ Long Yi* - yilong@nju.edu.cn; Yunxia Cao* - caoyunxia6@126.com \\ * Corresponding authors
}

Published: I December 2009

Reproductive Biology and Endocrinology 2009, 7:14| doi:|0.||86/|477-7827-7-|4|

This article is available from: http://www.rbej.com/content/7/I/I4I

(c) 2009 Xu et al; licensee BioMed Central Ltd.

This is an Open Access article distributed under the terms of the Creative Commons Attribution License (http://creativecommons.org/licenses/by/2.0), which permits unrestricted use, distribution, and reproduction in any medium, provided the original work is properly cited.

\begin{abstract}
Background: Polycystic ovary syndrome (PCOS) is a common endocrine disorder associated with an increased risk of type II diabetes mellitus. The results of previous research about the association of the VNTR polymorphism in 5-prime flanking region of the insulin (INS) gene with PCOS have been inconsistent. The present study was to investigate the association of the INSVNTR polymorphism with PCOS in a Han Chinese population.

Methods: The $-23 / \mathrm{Hphl}$ polymorphism as a surrogate marker of the INS-VNTR length polymorphism was genotyped by polymerase chain reaction and restriction fragment length polymorphism (PCR-RFLP) in 216 PCOS patients and 192 non-PCOS women as a control group. Allelic and genotypic frequencies were compared between patients and controls, and these results were analyzed in respect to clinical test data.

Results: No significant differences were observed between the cases and controls groups either in allele $(P=0.996)$ or genotype $(P=0.802)$ frequencies of INS-VNTR polymorphism; Regarding anthropometric data and hormone levels, there were no significant differences between INS-VNTR genotypes in the PCOS group, as well as in the non-PCOS group.

Conclusion: The present study demonstrated for the first time that the INS-VNTR polymorphism is not a key risk factor for sporadic PCOS in the Han Chinese women. Further studies are needed to give a global view of this polymorphism in pathogenesis of PCOS in a large-scale sample, familybased association design or well-defined subgroups of PCOS.
\end{abstract}

\section{Background}

Polycystic ovary syndrome (PCOS) is a common endocrine disorder affecting up to $4 \%$ of women of reproduc- tive age. The disorder is characterized by hyperandrogenism, menstrual irregularities and often central obesity. Moreover, it is associated with an 
increased risk of type II diabetes mellitus [1]. Colilla et al. demonstrated that there is a heritable component in betacell dysfunction in families of women with PCOS, and that heritability of beta-cell dysfunction is likely to be a significant factor in the predisposition to diabetes in PCOS [2].

The insulin (INS) gene locates at chromosome 11p15.5 and is one of established susceptibility locus to type II diabetes in Caucasians [3]. In the 5-prime flanking region of the INS gene, a variable number of tandem repeat (VNTR) regulates transcription of the gene; the shortest (class I) alleles were found to increase, whereas the longest (class III) alleles were observed to decrease in the patients in comparison to the controls $[4,5]$. It was reported that most class III alleles are associated with higher levels of INS transcription than class I alleles in the thymus [6,7]. The higher INS expression may more efficiently induce tolerance to insulin. An A/T single nucleotide polymorphism (SNP) located at -23 bp is highly linked with the INS-VNTR length polymorphism. The SNP can be digested by the restriction endonuclease HphI and exhibits restriction fragment length polymorphism which is called "-23/Hph I polymorphism" as a surrogate marker of the INS-VNTR length polymorphism [8].

The association between the polymorphism and PCOS has been observed in Caucasians but the results were inconsistent. Waterworth et al were the first to provide evidence on a linkage of PCOS with the INS gene VNTR locus and an association between VNTR class III alleles and the subset of anovulatory PCOS subjects [9]. A study of 74 UK women with PCOS reported an association between the class III allele and increasing severity of clinical phenotype [10]. On the contrary, three independent research groups failed to replicate the association [11-13]. On account of these controversial reports, the association has to be confirmed by independent studies in different ethnic groups. The purpose of the present study is to examine the genetic association of the $-23 / \mathrm{Hph}$ I polymorphism in the INS gene with PCOS in a Han Chinese population.

\section{Methods \\ Subject}

The subjects were recruited from patients who visited the Department of Obstetrics and Gynecology of the First Affiliated Hospital of Anhui Medical University during December 2005 and December 2006, including 216 PCOS patients and 192 non-PCOS women as a control group. The inclusion criteria of the PCOS group was based on the Rotterdam diagnostic criteria [14], while the eligibility criteria of non-PCOS women included: menstrual period $<35 \mathrm{~d}$ (most women had been pregnant or given birth to at least one child), precluding obesity, hirsutism, acne, excess sebum production and insulin resistance. All subjects were ethnic Han Chinese living in Anhui province and had not received hormonal therapy for at least 3 months before hormonal assays. After informed consent was obtained, blood was drawn from the subjects for hormonal assays and DNA analysis under the supervision of the Ethical Committee of the First Affiliated Hospital, Anhui Medical University. The peripheral blood was obtained between $8 \mathrm{AM}$ and 9 AM after a 12-hour overnight fast during the 3rd to the 5th day of the menstrual cycle.

\section{Hormonal assays}

The level of serum follicle-stimulating hormone (FSH), luteinizing hormone ( $\mathrm{LH})$, total testosterone $(\mathrm{T})$, estrogen (E2) and prolactin (PRL) were determined using Commercially available human chemiluminescence enzyme immunoassay kits (ROCHE DIAGNOSTICS GMBH, Mannheim, Germany). The intra- and inter-assay coefficients of variation of all the assays were less than $10 \%$.

\section{Genotyping}

Genomic DNA was prepared from peripheral blood leukocytes by using the Chelex-100 method [15]. INS-23/ Hph I polymorphism was determined using the polymerase chain reaction and restriction fragment length polymorphism (PCR-RFLP) method [12]. The PCR reaction mixture contained $50 \mathrm{ng}$ genomic DNA, $0.5 \mu \mathrm{M}$ of each primer (forward: 5'-AGC AGG TCT GTT CCA AGG-3' and reverse: 5'-CTT GGG TGT GTA GAA GAA GC-3'), 10 mM Tris- $\mathrm{HCl}$ (pH 9.0), $50 \mathrm{mM} \mathrm{KCl}, 1.5 \mathrm{mM} \mathrm{MgCl2,0.1 \%} \mathrm{Tri-}$ ton X-100, $0.2 \mathrm{mM}$ of each dNTP, and 0.75 unit Tag DNA polymerase (Promega, USA) in a final volume of $25 \mathrm{ml}$.

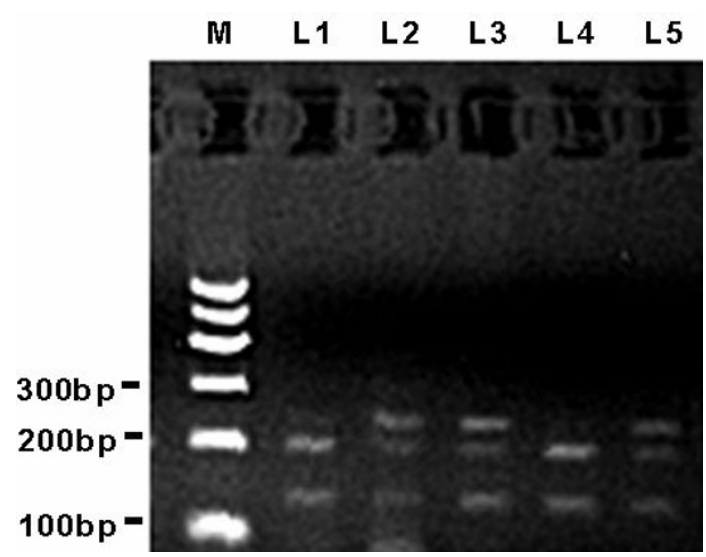

\section{Figure I}

Representative allele patterns of genotyping for INS$23 \mathrm{Hph}$ I polymorphism on $\mathbf{2 . 5 \%}$ agarose gel. M: DNA marker; $L I$ and L4: bands of 191 plus 129 bp indicating genotype AA; L2, L3 and L5: bands of 23I and I9I plus 129 bp indicating genotype $A T$; 
Table I: Anthropometric data and hormone levels of PCOS and non-PCOS groups

\begin{tabular}{|c|c|c|c|c|c|c|c|c|c|c|}
\hline Group & $\mathbf{N}$ & $\begin{array}{l}\text { Age } \\
\text { (years) }\end{array}$ & $\begin{array}{l}\text { Menarche } \\
\text { age } \\
\text { (years) }\end{array}$ & BMI $\left(\mathrm{kg} / \mathrm{m}^{2}\right)$ & $\begin{array}{l}\text { FSH } \\
(\mathbf{I U} / \mathrm{ml})\end{array}$ & $\begin{array}{l}\text { LH } \\
(\mathrm{IU} / \mathrm{ml})\end{array}$ & LH/FSH & $\begin{array}{l}\text { T } \\
\text { (nmol/L) }\end{array}$ & $\begin{array}{l}\text { E2 } \\
\text { (pmol/L) }\end{array}$ & $\begin{array}{l}\text { PRL } \\
\text { (ng/ml) }\end{array}$ \\
\hline PCOS & 190 & $\begin{array}{l}26.81 \pm \\
4.25^{*}\end{array}$ & $\begin{array}{l}14.49 \pm \\
1.62\end{array}$ & $23.08 \pm 3.65^{*}$ & $6.38 \pm 4.37$ & $\begin{array}{l}14.06 \pm \\
8.38^{*}\end{array}$ & $\begin{array}{l}2.40 \pm \\
1.27^{*}\end{array}$ & $\begin{array}{l}2.30 \pm \\
1.09 *\end{array}$ & $\begin{array}{l}228.32 \pm \\
166.28 *\end{array}$ & $\begin{array}{l}15.35 \pm \\
8.53\end{array}$ \\
\hline Non-PCOS & 157 & $\begin{array}{l}31.53 \pm \\
4.31\end{array}$ & $\begin{array}{l}14.66 \pm \\
2.4 \mid\end{array}$ & $21.27 \pm 2.24$ & $6.97 \pm 2.08$ & $4.46 \pm 2.10$ & $0.66 \pm 0.32$ & $1.65 \pm 3.92$ & $\begin{array}{l}179.75 \pm \\
143.00\end{array}$ & $\begin{array}{l}\mid 8.42 \pm \\
20.7 \mid\end{array}$ \\
\hline
\end{tabular}

Note: $* P<0.05$ vs non-PCOS. Some subjects whose hormone measurement is different from that presented in the Materials and Methods have been excluded.

The reaction mixture was subjected to denaturation at $96^{\circ} \mathrm{C}$ for $2 \mathrm{~min}$, followed by 30 cycles at $94^{\circ} \mathrm{C}$ for $1 \mathrm{~min}$, $62^{\circ} \mathrm{C}$ for $1 \mathrm{~min}, 72^{\circ} \mathrm{C}$ for $1 \mathrm{~min}$, then by a final extension at $72^{\circ} \mathrm{C}$ for $10 \mathrm{~min}$. The PCR products were $360 \mathrm{bp}$ and were digested with the $\mathrm{Hph}$ I restriction enzyme at $37^{\circ} \mathrm{C}$ for about $18 \mathrm{~h}$. After digested products were electrophoresed on a $2.5 \%$ agarose gel and visualized by ethidium bromide staining, the $\mathrm{T}$ and $\mathrm{A}$ alleles could be distinguished as bands of 231 plus $129 \mathrm{bp}$ and 191 plus 129 bp, respectively. Representative allele patterns of genotyping are illustrated in Figure 1.

\section{Statistical analysis}

The standard $X^{2}$ tests were used to compare allele or genotype frequencies in PCOS and non-PCOS groups and among different ethnic groups, and verify the HardyWeinberg equilibrium of genotype frequencies. The results of serum hormone levels were reported as MEANS \pm SD. Differences in anthropometric data and serum hormone levels between PCOS and non-PCOS groups were assessed by using Student's $t$-test. $P<0.05$ was considered significant for all tests. Statistical analyses were performed using the SPSS statistical software (SPSS Inc., Chicago, IL).

\section{Results}

Table 1 shows comparison of anthropometric data and hormone levels between PCOS and non-PCOS groups (some subjects whose hormone measurement is different from that presented in the Materials and Methods have been excluded). There is no significant difference in menarche age, FSH and PRL between the two groups. The BMI, serum LH, LH/FSH and serum T of the PCOS group are significantly higher than those of the non-PCOS group, which is consistent with the clinical characteristics of PCOS [14]. However, the level of E2 was also signifi- cantly higher in the PCOS group compared to the control. The unexpected result cannot be explained easily and further studies may be needed to address the issue.

The allele and genotype distributions for both PCOS and non-PCOS groups were consistent with the Hardy-Weinberg equilibrium, and are shown in Table 2. Frequencies of the allele $\mathrm{T}$ and genotype AT plus TT of non-PCOS ( $7.3 \%$ and $14 \%$, respectively) were significantly different to those previously published in the Japan population (3.3\% and 6.5\%, respectively, $P<0.05$ ) [16] and UK Caucasians (27.9 and 47.4, respectively, $P<0.05)$ [13]. In the association study, no significant difference between cases and controls was observed either in allele $(P=0.996)$ or in genotype $(P=0.802)$ frequencies, indicating that there was no association between INS-23/Hph I polymorphism and the incidence of sporadic PCOS cases in the Han Chinese population.

As indicated in Table 3, there was no significant difference regarding anthropometric data and hormone levels between INS-23/Hph I genotypes in the PCOS group and those in the non-PCOS group.

\section{Discussion}

The association of the VNTR polymorphism in 5-prime flanking region of the INS gene susceptible to type II diabetes with PCOS have been studied over the years in different populations, and the results observed have been inconsistent and controversial. No such data is available in the Han Chinese population. In the present study we have analyzed for the first time the association between the polymorphism of PCOS and anthropometric data and hormone levels.

Table 2: Allelic and genotypic frequencies of INS-23/Hph I polymorphism

\begin{tabular}{llllllll}
\hline Subjects & Allele $\mathbf{n}(\%)$ & T & P & $\begin{array}{l}\text { Genotype } \mathbf{n}(\%) \\
\text { A } / / \mathbf{A}\end{array}$ & A //T & T//T & P \\
\hline PCOS & A & $407(94.2)$ & $25(5.8)$ & 0.996 & $193(89.4)$ & $21(9.7)$ & $2(0.9)$ \\
Non PCOS & $356(92.7)$ & $28(7.3)$ & & $165(85.9)$ & $26(13.5)$ & $1(0.5)$ & 0.802 \\
\hline
\end{tabular}


Table 3: Anthropometric data and hormone levels of different INS genotypes in the PCOS and the non-PCOS groups

\begin{tabular}{|c|c|c|c|c|c|c|}
\hline \multirow[b]{2}{*}{ Index } & \multicolumn{3}{|c|}{ PCOS } & \multicolumn{3}{|c|}{ Non PCOS } \\
\hline & A/A & $A / T+T / T$ & $\mathbf{P}$ & $\mathbf{A} / / \mathbf{A}$ & $A / T+T / T$ & $\mathbf{P}$ \\
\hline$N(\%)$ & 173 (91.05) & $17(8.95)$ & - & 134 (85.35) & $23(14.65)$ & - \\
\hline Age (years) & $26.69 \pm 4.28$ & $27.94 \pm 3.93$ & 0.249 & $31.66 \pm 4.27$ & $30.74 \pm 4.60$ & 0.344 \\
\hline Menarch Age (years) & $14.46 \pm 1.58$ & $14.88 \pm 2.00$ & 0.301 & $14.67 \pm 2.52$ & $14.57 \pm 1.65$ & 0.846 \\
\hline $\operatorname{BMI}\left(\mathrm{kg} / \mathrm{m}^{2}\right)$ & $22.96 \pm 3.55$ & $24.30 \pm 4.52$ & 0.149 & $21.23 \pm 2.16$ & $21.49 \pm 2.68$ & 0.610 \\
\hline $\mathrm{FSH}(\mathrm{IU} / \mathrm{ml})$ & $6.43 \pm 4.55$ & $5.88 \pm 1.84$ & 0.625 & $6.96 \pm 2.17$ & $7.05 \pm 1.44$ & 0.851 \\
\hline $\mathrm{LH}(\mathrm{IU} / \mathrm{ml})$ & $14.30 \pm 8.64$ & $11.68 \pm 4.64$ & 0.221 & $4.43 \pm 2.09$ & $4.64 \pm 2.23$ & 0.670 \\
\hline LH/FSH & $2.47 \pm 1.29$ & $2.12 \pm 0.95$ & 0.347 & $0.66 \pm 0.31$ & $0.68 \pm 0.36$ & 0.155 \\
\hline $\mathrm{T}(\mathrm{nmol} / \mathrm{L})$ & $2.33 \pm 1.29$ & $1.99 \pm 0.87$ & 0.228 & $1.73 \pm 4.22$ & $1.24 \pm 0.89$ & 0.587 \\
\hline E2(pmol/L) & $225.11 \pm 163.90$ & $260.93 \pm 191.33$ & 0.398 & $179.79 \pm 139.70$ & $179.53 \pm 164.35$ & 0.994 \\
\hline $\operatorname{PRL}(\mathrm{ng} / \mathrm{ml})$ & $16.23 \pm 12.15$ & $16.97 \pm 8.31$ & 0.394 & $16.97 \pm 9.56$ & $26.87 \pm 49.01$ & 0.345 \\
\hline
\end{tabular}

Note: some subjects whose hormone measurement is different from that presented in the Materials and Methods have been excluded.

Some of PCOS phenotypes have been linked to the INSVNTR. Waterworth et al. were the first to provide the evidence on an association between VNTR class III alleles and the subset of anovulatory and hyperinsulinaemic PCOS subjects in a recessive genetic model [9]. Ferk et al. also found that Class III INS-VNTR alleles were significantly more frequent in the Slovene PCOS patients and the interaction of obesity and the III/III INS VNTR genotype might be a risk factor in the development of PCOS [17].

In this study, we demonstrate that there is no association between INS-23/Hph I polymorphism and PCOS in the Han Chinese population. Moreover, further analysis showed that there was no significant difference regarding anthropometric data and hormone levels between INSVNTR genotypes in the PCOS group, as well as in the nonPCOS group. The results were consistent to those previously reported [11-13]. After investigating 96 hyperandrogenic patients and 38 healthy control women, Calvo et al. concluded that there is no association between INS-VNTR and PCOS or hyperandrogenism, at least in Spanish women [12]. Subsequently, in a large-scale research on 255 nuclear families and about 3000 subjects from two populations (Britisher/Irisher and Finlander), Powell et al. revealed that INS-VNTR was not a key factor in the pathogenesis and progress of PCOS [13]. It should be noted that studies to date failed to confirm a significant association with the PCOS in general.

There are several possible explanations for these inconsistent results of association between the INS-VNTR and PCOS. Previous studies including this one showed the allele and genotype of the VNTR polymorphism in INS gene were different among ethical populations. Osawa et al. found the A allele frequency of $-23 / \mathrm{HphI}$ polymorphism was $97.4 \%$ in Japanese subjects, whereas in Europeans it was about $30 \%$ [18]. The results in this study showed the A allele frequency was about 93.5\% (Table 2).
Because of the predominance of class I over class III alleles in Asian population, further study with large-scale sample design is needed for us to ascertain the association between the INS-VNTR and PCOS. Case-control study is a common and powerful design to detect genetic contributions to complex diseases like PCOS. Unfortunately, a small portion of differences in allele frequencies between cases and controls could be attributable to diversity in background population, which is called population stratification. Family-based association designs like transmission disequilibrium test measure the over-transmission of an allele from heterozygous parents to affected offsprings. The designs do not use control groups and can overcome this disadvantage effectively [19], and would be an alternative way to assess the risk of PCOS.

In this study, we did not assess Insulin levels and Insulin resistance of the subjects. We will address the issue of whether subgroups of PCOS are associated with INSVNTR polymorphism by investigating clinical and biochemical features related to glucose metabolism among PCOS women.

\section{Conclusion}

The present study demonstrated for the first time that the INS-VNTR polymorphism is not a key risk factor in sporadic PCOS in the Han Chinese women. Further studies are needed to give a global view of this polymorphism in pathogenesis of PCOS in a large-scale sample, familybased association design or well-defined subgroups of PCOS.

\section{Competing interests}

The authors declare that they have no competing interests.

\section{Authors' contributions}

YC and LY conceived and designed the study. LY, QG and YW contributed the data analysis and drafted the manuscript. YX, ZW and ZZ carried out the molecular genetic 
studies. QY, PH and carried out the immunoassays. XZ and GG performed collection of blood samples. All authors read and approved the final manuscript.

\section{Acknowledgements}

We thank Professor Faming Pan from Department of Epidemiology and Biostatistics, School of Public Health, Anhui Medical University for statistical help. This work was supported by grants from the National Natural Science Foundation of China (30571954) and the Nature Basic Research Program of China (973 Program 2010CB945I03).

\section{References}

I. Xita N, Georgiou I, Tsatsoulis A: The genetic basis of polycystic ovary syndrome. Eur J Endocrinol 2002, 147:717-725.

2. Colilla S, Cox NJ, Ehrmann DA: Heretability of insulin secretion and insulin action in women with PCOS and their first degree relatives. J Clin Endocrinol Metab 200I, 86:2027-203I.

3. Harper ME, Ullrich A, Saunders GF: Localization of the human insulin gene to the distal end of the short arm of chromosome I I. Proc Natl Acad Sci USA 198I, 78:4458-4460.

4. Bell GI, Horita S, Karam JH: Apolymorphic locus near the human insulin gene is associated with insulin-dependent diabetes mellitus. Diabetes 1984, 33: 176-183.

5. Pugliese A, Miceli D: The insulin gene in diabetes. Diabetes Metab Res Rev 2002, I 8: 13-25.

6. Vafiadis P, Bennett ST, Todd JA, Nadeau J, Grabs R, Goodyer CG, Wickramasinghe S, Colle E, Polychronakos C: Insulin expression in human thymus is modulated by INS VNTR alleles at the IDDM2 locus. Nat Genet 1997, 15:289-292.

7. Pugliese A, Zeller M, Fernandez A Jr, Zalcberg LJ, Bartlett RJ, Ricordi C, Pietropaolo M, Eisenbarth GS, Bennett ST, Patel DD: The insulin geneis transcribed in the human thymus and transcription levels correlated with allelic variation at the INS VNTRIDDM2 susceptibility locus for type I diabetes. Nat Genet 1997, I 5:293-297.

8. Lucassen AM, Julier C, Beressi JP, Boitard C, Froguel P, Lathrop M, Bell Jl: Susceptibility to insulin dependent diabetes mellitus maps to a 4.1 kb segment of DNA spanning the insulin gene and associated VNTR. Nat Genet 1993, 4:305-310.

9. Waterworth DM, Bennett ST, Gharani N, McCarthy MI, Hague S, Batty S, Conway GS, White D, Todd JA, Franks S, Williamson R: Linkage and association of insulin gene VNTR regulatory polymorphism with polycystic ovary syndrome. Lancet 1997, 349:986-989.

10. Michelmore K, Ong K, Mason S, Bennett S, Perry L, Vessey M, Balen $A$, Dunger $D$ : Clinical features in women with polycystic ovaries: relationships to insulin sensitivity, insulin gene VNTR and birth weight. Clin Endocrinol (Oxf) 200I, 55:439-446.

II. Vanková M, Vrbíková J, Hill M, Cinek O, Bendlová B: Association of insulin gene VNTR polymorphism with polycystic ovary syndrome. Ann N Y Acad Sci 2002, 967:558-565.

12. Calvo RM, Tellería D, Sancho J, San Millán JL, Escobar-Morreale HF: Insulin gene variable number of tandem repeats regulatory polymorphism is not associated with hyperandrogenism in Spanish women. Fertil Steril 2002, 77:666-668.

13. Powell BL, Haddad L, Bennett A, Gharani N, Sovio U, Groves C], Rush K, Goh MJ, Conway GS, Ruokonen A, Martikainen H, Pouta A, Taponen $S$, Hartikainen AL, Halford S, Zeggini E, Järvelin MR, Franks $S$, McCarthy MI: Analysis of multiple data sets reveals no association between the insulin gene variable number tandem repeat element and polycystic ovary syndrome or related traits. J Clin Endocrinol Metab 2005, 90:2988-2993.

14. The Rotterdam ESHRE/ASRM-Sponsored PCOS Consensus Workshop Group: Revised 2003 consensus on diagnostic criteria and long-term health risks related to polycystic ovary syndrome. Fertil Steril 2004, $81: 19-25$.

15. Walsh PS, Metzger DA, Higuchi R: Chelex 100 as a medium for simple extraction of DNA for PCR-based typing from forensic material. Biotechniques 1991, 10:506-513.

16. Awata T, Kawasaki E, Ikegami H, Kobayashi T, Maruyama T, Nakanishi K, Shimada A, lizuka H, Kurihara S, Osaki M, Uga M, Kawabata Y, Tanaka S, Kanazawa Y, Katayama S: Insulin gene/IDDM2 locus in Japanese type I diabetes: contribution of class I alleles and influence of class I subdivision in susceptibility to type I diabetes. J Clin Endocrinol Metab 2007, 92: I79|-I 795.

17. Ferk P, Perme MP, Gersak K: Insulin gene polymorphism in women with polycystic ovary syndrome. J Int Med Res 2008, 36:1180-1187.

18. Osawa $H$, Onuma $H$, Murakami A, Ochi M, Nishimiya T, Kato $K$, Shimizu I, Fujii Y, Ohashi J, Makino H: Systematic search for single nucleotide polymorphisms in the insulin gene: evidence for a high frequency of -23T-A in Japanese subjects. Biochem Biophys Res Commun 200I, 286:45I-455.

19. Cardon LR, Palmer LJ: Population stratification and spurious allelic association. Lancet 2003, 36 I:598-604.
Publish with Biomed Central and every scientist can read your work free of charge

"BioMed Central will be the most significant development for disseminating the results of biomedical research in our lifetime. "

Sir Paul Nurse, Cancer Research UK

Your research papers will be:

- available free of charge to the entire biomedical community

- peer reviewed and published immediately upon acceptance

- cited in PubMed and archived on PubMed Central

- yours - you keep the copyright
BioMedcentral 